\title{
The Instrument as Instrumental: Pgaz k' Nyau Bamboo Musicking and Karen Eco-Friendliness
}

\author{
Suwichan Phatthanaphraiwan \\ Bodhivijjalaya College, Srinakharinwirot University, Thailand \\ e-mail: suwichan@g.swu.ac.th \\ Benjamin S. Fairfield \\ University of Hawai'i at Mānoa \\ e-mail: bsf@hawaii.edu \\ DOI: https://doi.org/10.37134/mjm.vol8.4.2019
}

Published online: 15 November 2019

Cite this article (APA): Phattanaphraiwan, S., \& Fairfield, B. S. (2019). The Instrument as Instrumental: Pgaz k'Nyau

Bamboo Musicking and Karen Eco-Friendliness. Malaysian Journal of Music, 8, 68-85.

https://doi.org/10.37134/mjm.vol8.4.2019

\begin{abstract}
While the tehnaku, the iconic six-string curved neck harp of the Pgaz k'Nyau (Sgaw Karen) people has made a strong comeback after $19^{\text {th }}$ and $20^{\text {th }}$ century, scholars lamented its demise, many other traditional bamboo instruments of the Pgaz k'Nyau still remain little-known, not only in academia but increasingly within Pgaz k'Nyau communities themselves, due in part to national forestry laws, resettlement and evictions, modernisation campaigns, and an increasing scarcity of, or restricted access to, certain natural and cultural resources. This ethnographic study investigates the various uses of bamboo in two Pgaz k'Nyau communities in Thailand, illustrating the importance of local knowledge of natural resources and the place of bamboo in shaping Pgaz k'Nyau music, ethics, aesthetics, ecological activity, beliefs and social relations. Bamboo musical instruments, in legends and in everyday application, are co-created with help from rodents and insects, lure wild pigs from the forest, bookend human lifecycles, help to confine spirits to the forest and the afterlife and are reworked from pig troughs into slit-drums used to drum up communal action. This research discusses how these increasingly rare bamboo musical instruments speak to a variety of contemporary contextual issues faced in Pgaz k'Nyau communities. We argue that Pgaz k'Nyau bamboo is instrumental in reflecting and perpetuating longstanding eco-friendly cultural practices embodied in a five-part Pgaz k'Nyau prescription for managing ecological relations within the self, between self and other, between the human and animal world, between human and forest, and between human society and the supernatural world; and it does so in response to Thai political narratives that have inappropriately labelled the Pgaz k'Nyau as destroyers of national forests.
\end{abstract}

Keywords: bamboo musical instruments, ecomusicology, Pgaz k’ Nyau, Sgaw Karen, Thailand

\section{Borders, Belonging and Bamboo}

The national anthem, adopted in 1939 when 'Siam' became 'Thailand', proclaims: 'Thailand unites the flesh and blood of all Thais.' Yet the ethnonational label and legal status of 'Thai' was not readily available to all groups who lived within the borders of the nation-state. Scholars point to a cultural revolution as the multi-cultural Kingdom of Siam transitioned officially to the ethnicallyspecific nation of 'Thailand' in 1939, where lowland Thai leaders enforced official modernisation and assimilation measures in an effort to civilise the highland peoples (Forbes, 1982, p. 1059; Jory, 
1999, p. 338; Numnonda, 1978, pp. 235-236). Siam as a kingdom had never in its history been a mono-cultural society, but $20^{\text {th }}$ century Thai nationalist rhetoric eventually came to overtake and overlook the non-Thai ethnic groups and indigenous populations within its newly created national borders. Even today, when official narratives speak of Thai culture, central Thai culture is the primary referent-variance, marginality, regionalism, or 'dialect' serve as outliers that confirm the majority (Wongthes, 2011, pp. 1-8; Winichakul, 2011, p. 33). One can be 'southern Thai' or 'ThaiLao' or 'Lanna-Thai', but the national and ethnic border remains a fixed part of accepted identity.

A step further removed from these regional-yet-still-Thai populations are the often misunderstood highland groups -Hmong, Mien, Akha, Lisu, Lahu, H'tin, Lu, Khamu, and Karen ${ }^{1}-$ who, though diverse in livelihood and agricultural methods, were typically classed together, at least into the 1980s, under monolithic labels such as 'forest destroyers and opium growers' (Laungaramsri, 2003, p. 37) or the 'hill tribe problem' (Buadaeng, 2006, pp. 361; McKinnon, 2011, pp. 56-61). 'Hill tribes' and their actual or assumed destructive agricultural methods made them enemies of a state seeking to stem the tide of deforestation, and stereotypical narratives had the effect of devaluing indigenous cultures while justifying the eviction and resettlement of indigenous populations living in newly-claimed 'protected' forest preserves (Buergin, 2003). Indigenous groups also lack institutional support when it comes to perpetuating local knowledge, largely due to the legacy and history of central government assimilation policies and programmes that sought to, forcibly at times, turn all indigenous groups into Thais (Kesmanee, 1994; Forbes, 1982, p. 1065; Jonsson, 2004, p. 677; p. 685; Hayami, 1996, p. 345). For example, indigenous languages are explicitly or implicitly forbidden in local schools in highland communities out of the concern that indigenous populations speak Thai poorly. That these ideas are internalised and perpetuated by indigenous populations themselves can be seen in the assessment of Sgaw Karen scholar Esther Dangpongpee, who remarked,

\begin{abstract}
We have to do something so that the Karen may know the value of our people and not see other cultures and traditions as better than ours. It's not because others came and made us lose our culture but that our people are losing our own culture. That's the biggest problem ... In this area [Huay Kaew, Chiang Mai], most of the people are Karen but their children never speak Karen anymore.
\end{abstract}

When they go to school, they never use Karen. Some of the parents, they think we are a tribal people, from the mountain, so we don't speak Thai very well. So they want their children to speak Thai like real Thai, so they try to let their children speak Thai. Even at home they don't speak Karen, so that is the way to make our language and culture to be lost. This is the problem. If we do not try to do something to preserve it, the next generation will lose it. (personal communication)

Assimilation, then, offers one way of resolving the ethnic dissonance. Another option is to closely evaluate, prove, and broadcast an alternative understanding of the ethnic group - one that is decisively eco-friendly and grounded in an ecological symbiosis of human, nature, and culture. Given the Thai labelling of highlanders as destructive and state-sanctioned evictions from forested areas, culminating most recently in the disappearance and murder of a Pgaz K'Nyau activist who tried to sue forest officials for the destruction of a Karen settlement in Kaeng Krachan National Park (Singkiree, 2019), a strategic and urgent appeal to eco-indigeneity has evolved into a near 'consensus' for Sgaw Karen (Pgaz k’Nyau) spearheaded by activists, academics, and NGOs (Walker, 2001). ${ }^{2}$ Andrew Walker's critique of the so-labelled 'Karen consensus' is noteworthy for problematising the notion of ' $a$ ' or 'the' Karen people (who are in reality a conglomeration of various Tibeto-Burman mutually unintelligible language groups and sub-groups further separated by national borders, adopted religious systems, and customs), as the logic of Karen indigenous identity via eco-friendly practice has contemporarily outshone other modern alternative narratives of Karen 
identity formation. Nowadays, due to decades of activism and campaigns, 'the' 'Karen' are increasingly known as 'the eco-friendly' hill tribe (Henry Delcore, 2007, p. 101). We do not propose that there is or should be one monolithic notion of Karen-ness. There is, however, ample evidence and oral tradition at hand to support the idea of symbiotic relations between Sgaw Karen (Pgaz k'Nyau) and the natural world, and NGOs and activists seize these upon as they speak to contemporary needs and political realities.

This study takes Sgaw Karen eco-activism as given, logically extending it into the realm of traditional bamboo instruments to paint a larger, integrated picture of what Dirksen (2019) calls 'communion' (p. 47), or the connective and overlapping categories of cultural, natural, and spiritual for above-mentioned political application. Proven, yet again, in this endeavour is a corpus of assumed and shared values, beliefs, and practices deeply intertwined with nature and vested in its perpetuation - in other words, more proof that 'the Karen' are not 'forest destroyers'. Problematic, however, is the steady decline of access to resources (natural, spiritual, and ancestral/elder) that enable not only the songs and stories but also the instruments themselves, which embody deep connections among the varied players (human, animal, natural, supernatural) that formulate Sgaw Karen society to endure.

Our study specifically focuses on bamboo musical instruments among the Pgaz k'Nyau (rather than the more commonly known tehnaku harp, kwae buffalo horn and klo bronze frog drum) for three reasons. First, for Pgaz k'Nyau communities in Thailand, bamboo is of crucial importance for various aspects of everyday life, which includes and is mediated by music. Secondly, knowledge of these instruments has neither received sufficient academic attention nor been systematically recorded to date (the principal investigator's planned outgrowth of this project is an applied pedagogical project involving instrument construction and instruction). Lastly, this research can offer a model for ethnographic data collection for successive research projects, for the Pgaz k'Nyau specifically and for other ethnic groups more broadly. ${ }^{3}$

Bamboo is embedded, in contemporary practice or at least in collective memory within the two Pgaz k'Nyau communities studied here (the animist site still retains much of the traditional practice, while the Christian site still has elders who have experienced Pgaz k'Nyau culture pre- and post-conversion and can recall and reinterpret legends related to bamboo instruments). We argue that the instruments are instrumental to community relations. Bamboo affords communication, tempers the self, signifies new life, orders life transitions, positions spirits (varyingly, depending on religious practice), and frames the fabric of Pgaz k'Nyau society. The first location studied includes Ban Mai Phattana and Ban Nong Chet Nuai villages of Kalyani Wattana district, Chiang Mai, which are two Christian sites fairly well known for their Pgaz k'Nyau bamboo dance (they have been the subject of more than 10 Thai TV documentaries). Second is Kaeng Krachan district in Petchaburi province, which includes traditional animist Pgaz k'Nyau communities, known for their construction of bamboo musical instruments no longer found in Pgaz k'Nyau communities in northern Thailand (Figure 1). The principal investigator visited this area accompanied by TV crews of two Thai PBS programs (Sinlapawattanatham and Phansaengrung) during February of 2012. 


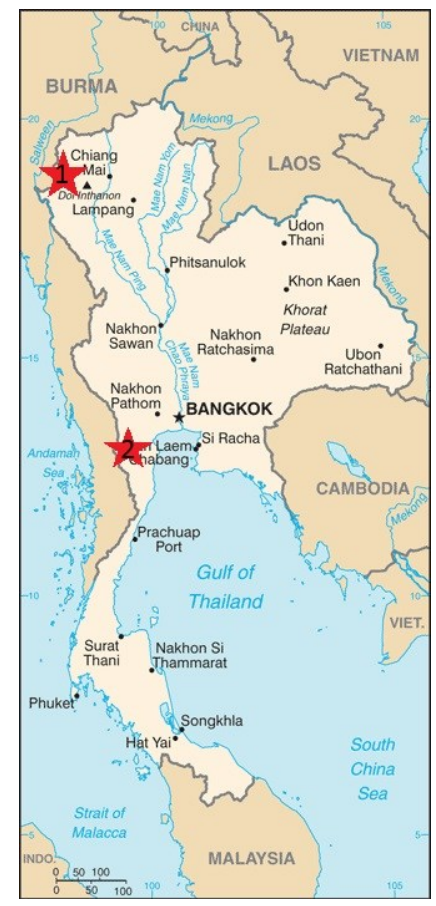

Figure 1. Map of Thailand (Source: Map of Thailand, The World Factbook, Retrieved from https:/www.cia.gov/library/publications/the-world-factbook/attachments/maps/TH-map.gif)

\section{Research Motivations, Objectives and Structure}

Christopher Small's notion of Musicking (1998) significantly expanded the reach and understanding of music from objective product to processual and cultural activity. Such a view posits music as a mediator and reifier of relationships, a tool and site of a social process at work. Steve Waksman applies this idea to the 'reading' of not just music and musical settings but musical instruments, proposing that we examine physical instruments not as static materials but as entwined in the process of forming relationships in the ecological sense, signified with meaning and interacting with human, spiritual and natural environments. He argues,

Musical instruments, it might be said, represent the first points at which sound moves from a strictly material acoustic phenomenon to an organised medium of social and cultural expression that, in turn, has implications for the ways that individuals relate to one another or for the broader organisation of social relationships (2003, pp. 253-254)

Stated differently, instruments don't make just music. They make society or culture; Dawe asserts that instruments make 'place' as well (2016, p. 109). And, as Titon notes, they do so with a sense of urgency in a time of 'ecological crisis' (2016, p. 67), which, especially among the Pgaz k'Nyau, is also clearly a cultural crisis (p. 78). Humans are not the sole driving agent in the conversion from natural to cultural object. Nature has affordances and naturally shapes human thought (Dawe, 2016, p. 118). Our research on Pgaz k'Nyau usage of bamboo is framed within ecomusicology, defined by Dawe as encompassing "The study of music, culture, and nature in all the complexities of those terms" and encompassing "musical and sonic issues, both textual and performative, related to ecology and the natural environment" (2016, pp. 1-2). Dawe insists that organology has been too focused on the product, neglecting the physical and cultural process of instrument construction (p. 119). We seek to address that process (construction and signification) here, and we do not idealise these bamboo instruments as inherently or statically 'authentic' by virtue of their nature but rather recognise them as a tool for projecting or constructing useful notions of authenticity (p. 256), even as 
we acknowledge that term's problematic yet useful discursive applications. Data is needed first, though, and our two main objectives are as follows:

1. To gather data about Pgaz k'Nyau communities' cultural use of bamboo for making instruments.

2. To analyse the origins, meanings and ecological implications of different types of bamboo musicking among the Pgaz k’Nyau.

\section{Methodology}

The principal investigator led a team of researchers who employed qualitative ethnographic research methods, building rapport with key community leaders in both sites to ensure goals were communicated and site visits were conducted in accordance with local customs, observing instrument construction and performances, conducting in-depth interviews (both structured and unstructured) in the local language and recording audiovisual documentation. The team collected, stored and analysed targeted information, translated the results from Pgaz k'Nyau into Thai and coded and verified the data through inter-coder reliability procedures.

We focused on four regional bamboo instruments: the pi-ba (aerophone), the pi-u or $u$-maw (aerophone), the koe-lo (idiophone) and the saw-tru (chordophone). In the following section, we outline for each instrument,

1. The history and origins of each.

2. Restrictions associated with making and playing them.

3. Their underlying value and meaning in Pgaz k’Nyau society.

\section{$\boldsymbol{P i - b a}$ (ปิ๊บา)}

Though rare and largely unknown to outsiders, Pgaz k'Nyau-style multi-tube bamboo free-reed aerophones can still be found (Figure 2) in various areas within Kalyani Wattana and in Kaeng Krachan districts. The pi$b a$ is a free-reed aerophone with seven pairs of bamboo pipes near the Pgaz k'Nyau communities in Pong Luek-Bangkloi, Kaeng Krachan district, Petchaburi province. Currently in this area there are only ten known elders who still possess the knowledge to play the $p i-b a$, and those who know how to construct the instrument have dwindled to just one person. Added to this scarcity, the type of bamboo needed (saw kgae) to construct a $p i-b a$ is increasingly rare, as is, more crucially, the motivation to play and make the instrument.

Political realities have worked to shape the instrument's demise. Jaw-bwae, 78-years-old, 'legally' known as Somchit Suphangkun (as Karen names in his generation were not allowed to be officially registered), is said to be the sole person in Kaeng Krachan left who knows how to construct a pi-ba. ${ }^{4} \mathrm{He}$ recalled,

Since we were evicted from our traditional lands (in what is now Kaeng Krachan National Park) and moved down here, we have encountered a multitude of problems: landlessness, unemployment, ineligibility to work, difficulty in the city when we have sick or injured that need medical attention, and inability to forage in our traditional home. It has been difficult, not just to retain and play our music, but to survive.

Now, when someone wants a pi-ba, they must go purchase one in Ratchaburi or a neighbouring province. Sometimes they just go buy a similar-looking khaen in the northeast (Isaan) region and make adjustments to it (removing a few pipes so that seven pairs are left) so that it works the same as the Pgaz k'Nyau pi-ba. 


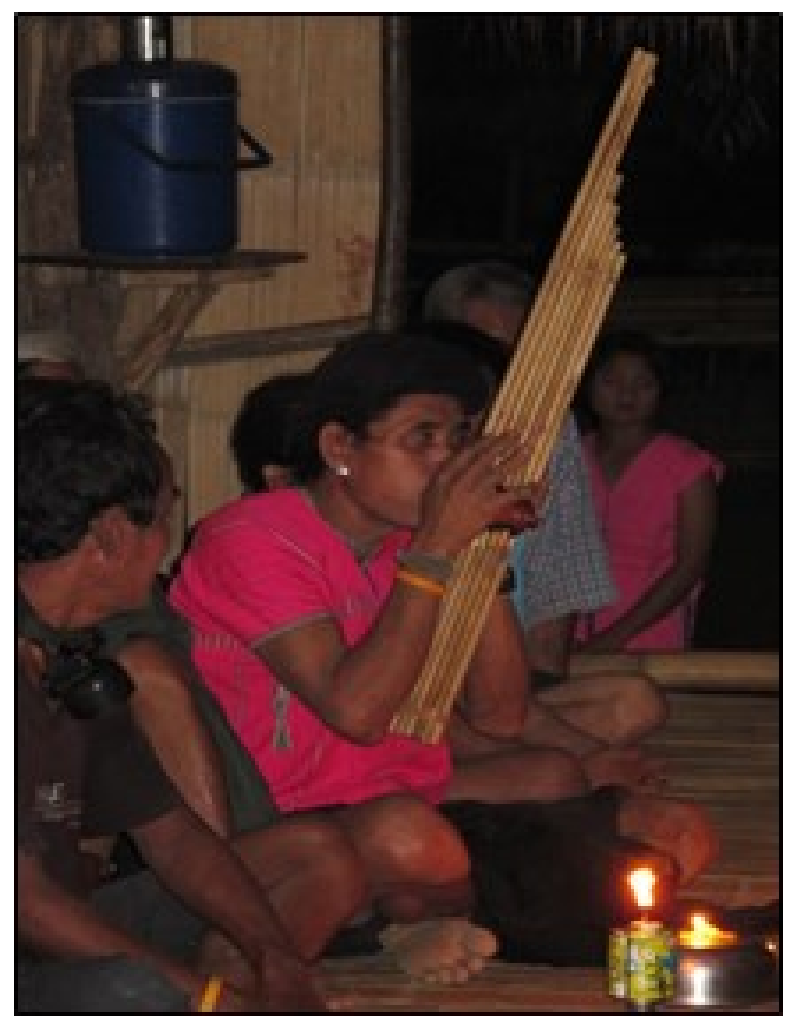

Figure 2. Young Karen man plays the pi-ba (Source: Suwichan Phattanaphraiwan, October 9, 2013)

\section{History and Origins}

Jaw-bwae explained that, according to Karen legend, the first pi-ba maker was Koejaklaw, the heavenly being who created the earth. ${ }^{5}$ As the legend goes, Koejaklaw possessed many of the same characteristics as the Pgaz k'Nyau people, and made his living like any ordinary farmer. Pgaz k'Nyau oral histories teach that the higher elevation bamboo forests provided good spots for agriculture, since Koejaklaw went up there looking for land near the bamboo groves and settled in a grove of saw kgae bamboo. Before clearing some land for planting, Koejaklaw gazed upon the saw kgae and removed a handful of the most beautiful stalks.

After the land had been cleared, Koejaklaw set his mind to constructing a musical instrument. He took the bamboo stalks and cut them into seven pairs. The first two pairs were made to be the same length, while pairs 3-7 were cut to be about 2 inches shorter than the previous pair. After this, Koejaklaw carved holes in each stalk and inserted a metal lamella into each space, similar to the kwae (a Pgaz k'Nyau aerophone with a free-reed inserted into the horn of a buffalo). From there, the pipes were aligned and lashed together in paired sets. Next, a piece of wood was carved into a mouthpiece. Koejaklaw tried blowing into it, but no sound came out, no matter how he tried. In the end, he gave up and left the useless pi-ba on a stump in the field.

Koejaklaw eventually forgot all about the instrument he had made. But one day, as the season turned and the grass and rice seedlings were sprouting, Koejaklaw went out to weed the fields near the spot where he had left the instrument. By this time, some of tubes had in places been chewed through by rats; in others, termites had bored holes through. When Koejaklaw saw this, he picked it up and knocked it against a stump to remove the dust and droppings. With the addition of these 'finger holes,' the instrument now produced sound. For the rest of that day, wherever Koejaklaw sat, stood and meandered around, he blew incessantly into the instrument. People passing by saw it and heard a sound, stopping to sit and listen. Nowadays it is played for various celebrations. 


\section{Restrictions in Constructing and Playing the Pi-ba}

The folklore attached to the pi-ba informs Pgaz k'Nyau ecological activity and taboo. Care must be taken not to harm or kill rats and termites when constructing this instrument, as it is believed that these beings help to forge the seminal pi-ba. The instrument's manufacturing demands that one have a spirit of respect for the animals that share the natural world with the Pgaz K'Nyau. Musical performance demands one learn not just the fingerings but be conscious of the potential loss of life as well as the contributions from the natural world. Literally, the name pi-ba, means 'flute of respect': when played, the shape of the player's hands forms a wai gesture normally used to greet one's fellow community member (Figure 2), so the spirit of respect (extending to human and nature) is also physically embodied in the playing posture.

\section{Values, Meaning and Philosophies underlying the Pi-Ba}

According to Jaw-bwae,

The ancestors said that every time we blow on the $p i-b a$, we must think of the rat and the termite, which also played a role in the production of the pi-ba. For this reason, the Pgaz k'Nyau people do not eat rats found living in human dwellings. The pi-ba players especially would not kill rats, eat rats, kill termites, or destroy a termite mound. If they violated this rule, their playing would no longer be enjoyable to any audience. (personal communication, October 2015)

The call to avoid the consumption of house rodents also appears in tha (Pgaz k'Nyau poetic oral tradition consisting of 7-syllable rhyming couplets):

pwa mi loe ploe due yue doe, pwa pwa loe ploe due yue doe, pho sa khae i toe due loe, toe goe mi goe pwa ba loe.

Translated as:

Our ancestors did not eat house mice,

The elders of old would not consume house rats;

If their offspring do not also refrain,

Their lives will be cut short, their spirits will not last.

Basically, learning to the play the $p i-b a$ involved much more than learning the notes or fingerings. To learn music is thus to learn to gratitude and respect for the natural world. Players learn to take precautions and work with patience, ensuring they would not cause the death of rats or termites. If one can learn patience and proper conduct according to these strictures, he can then develop skills to avoid other kinds of evil.

Moreover, the Pgaz k'Nyau also use the $p i-b a$ as symbolic of the ethnic group's basic philosophical paradigm: unified, inclusive, cooperative and harmonious. For example, the individual's potential within the community is sometimes compared to the fingers: each is needed to play a certain note on the pi-ba's many pipes. Every finger has its own responsibility. If you are missing one pipe, or one finger, the song cannot be complete. This metaphor extends to every individual having a role and responsibility in the community, and everyone has value, use and importance within the larger Pgaz k'Nyau society. Respecting, accepting and honouring others are an important trait for humanity, as humans are eco-social creatures and cannot survive in isolation. Everyone has a role, everyone matters and everyone deserves respect (hence the name and physical playing posture for the 'flute of respect'). 


\section{Pi-u, or U-maw (ปิ๊eู / อูมอ)}

The pi-u, or $u$-maw (Figure 3), is a transverse flute (aerophone) made from saw khae bamboo. There are a total of 7 holes in it ( 6 for pitch). If the name were translated from Pgaz k'Nyau directly, pi means flute and $u$ means 'to blow.' As for the alternate name, $u$-maw, maw refers to a joint of bamboo ( $u$ still means blow). We encountered this instrument in Ban Mai Phattana of Chaem Long sub-district in Kalyani Wattana district, Chiang Mai, where there was just one person left who still produces these instruments (though there are ongoing informal programs there for teaching the youth to play it, including efforts mentioned in endnote 6).

The producer of the $p i-u$ faces obstacles: the saw khae bamboo used to make the $p i-u$ has of late been on the decline, so much so that nowadays it can only be found in one watershed and is in danger of going extinct. ${ }^{6}$ It is sometimes used to make fishing poles and traps.

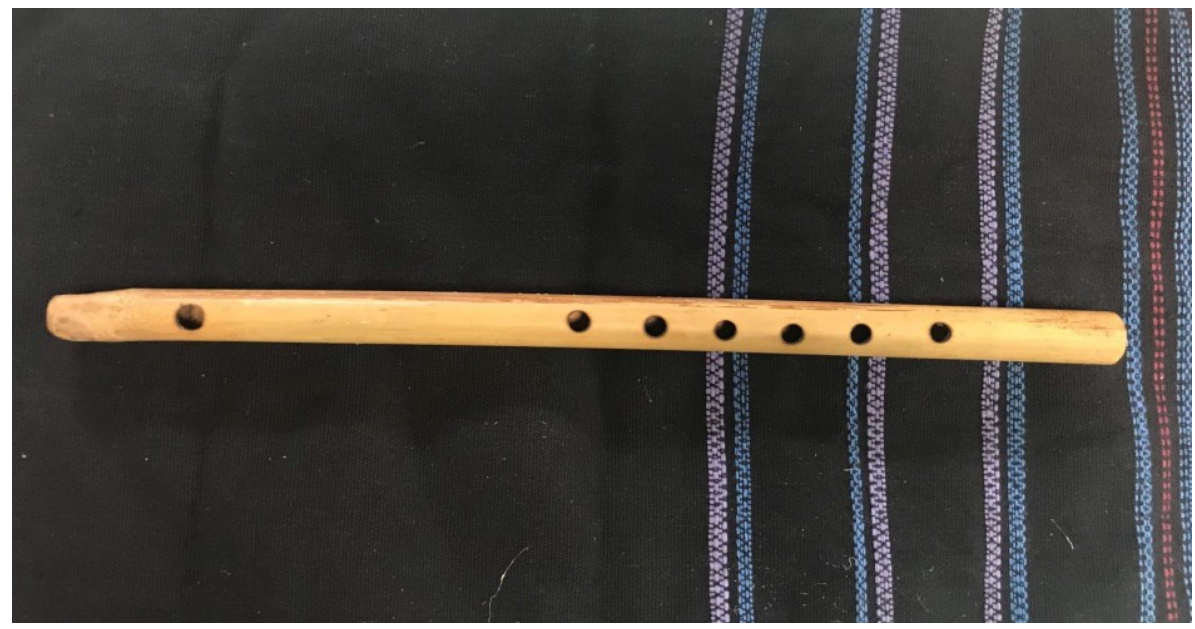

Figure 3. Picture of pi-u (u-maw) (Source: Chi Suwichan Phattanaphraiwan, October 3, 2019)

\section{History and Origins}

Phana Phattanaphraiwan, 69-years-old, a local Pgaz k'Nyau artist in Ban Mai Phattana village of Chaem Luang sub-district, Kalyani Wattana district, described the role of bamboo in Pgaz k'Nyau birthing procedures. When a child was born, the midwife was to follow specific steps, which included important strictures on the handling the umbilical cord and placenta. They had to use freshly cut, sharp bamboo as the tool for severing the cord. Pgaz k'Nyau believed that the bamboo that could attain the sharpest edge was the saw khae variety. They compared its strength and sharpness to the edge of a knife.

Bamboo in the khae family consists of various types: saw khae and khe me are both very sharp (khe in Pgaz k'Nyau translates as knife). Bamboo is cleaner and safer than an iron blade, which can gather rust and can be dangerous in such a delicate operation. Phana asserts that, relating to the origins of the $u$-maw or $p i-u$,

While the mother was recovering, the husband would take saw khe bamboo joints left over from the cord cutting, blowing through them to stoke the fire for his wife, who needed to stay warm. As he kept blowing, a sound began to emerge, and the pitch would change if a hole in the node was covered over. The father thus busied himself burning small holes into the tube. But upon further experimentation, it was not very loud, so he took some of the boiling porridge (the pig feed) and closed up some of the open holes before blowing through it again. The volume intensified. After this, he simply would not put it down, and played it for his wife at the fireside. He played his new instrument so much, in fact, that his wife began to get rather annoyed and complained, asking, "Would you please stop $u$-maw/pi-u (blowing on that bamboo) for a while? The cacophony 
is too much." From then on, when anyone asked what it was called, they referred to it as $u$-maw or pi-u (blowing on the bamboo) (personal communication, December 27, 2015)

\section{Restrictions in Constructing and Playing the $U$-maw}

In the past, when one had a child or had leftover bamboo joints from the cutting of the umbilical cord and made a pi-u/u-maw, the mere presence and possession of these khe cuttings communicated to all the fact that a birth had occurred recently. The birth of a child was thus paired with the 'birth' of a pi-u. Thus, one could not go out and cut arbitrarily at will just because one wanted to make an instrument. It was believed, in fact, that if this occurred, not only would the $p i-u$ sound terrible but the bamboo grove that the cutting was made from would die out completely. Another restriction held that women were not allowed to cut the bamboo because it would cause the grove to flower and die. Here, the use of natural resources was inextricably linked to and determined by social needs rather than individual desire.

\section{Values, Meaning and Philosophies underlying the $\boldsymbol{U}$-maw}

The pi-u/u-maw's meaning, and its value, is birth. The creation of a $p i-u$ is paired with the birth of a child. Additionally, though, while one of its functions was performance post-labour, it was also paired with death and played for the funeral activity called jikli (a bamboo dance where dancers step or hop outside a grid of bamboo poles that are clicked together on the beat (Figure 4). One would hear the phrase, jikli u-maw at a funeral. Jikli is a signal of death, a fate which no human can escape. We are born, we live, we eventually will pass on. We arrive with nothing and we take nothing with us, and the $p i-u$ was present at both life transitions.

To play the pi-u/u-maw requires that breath be sent through the bamboo. When one stops blowing, the sound ceases. This acts a metaphor for human life for the Pgaz k'Nyau. One day, our breathing will cease. While living, our breathing produces sounds and melodies, allowing others to learn, remember and benefit from our existence.

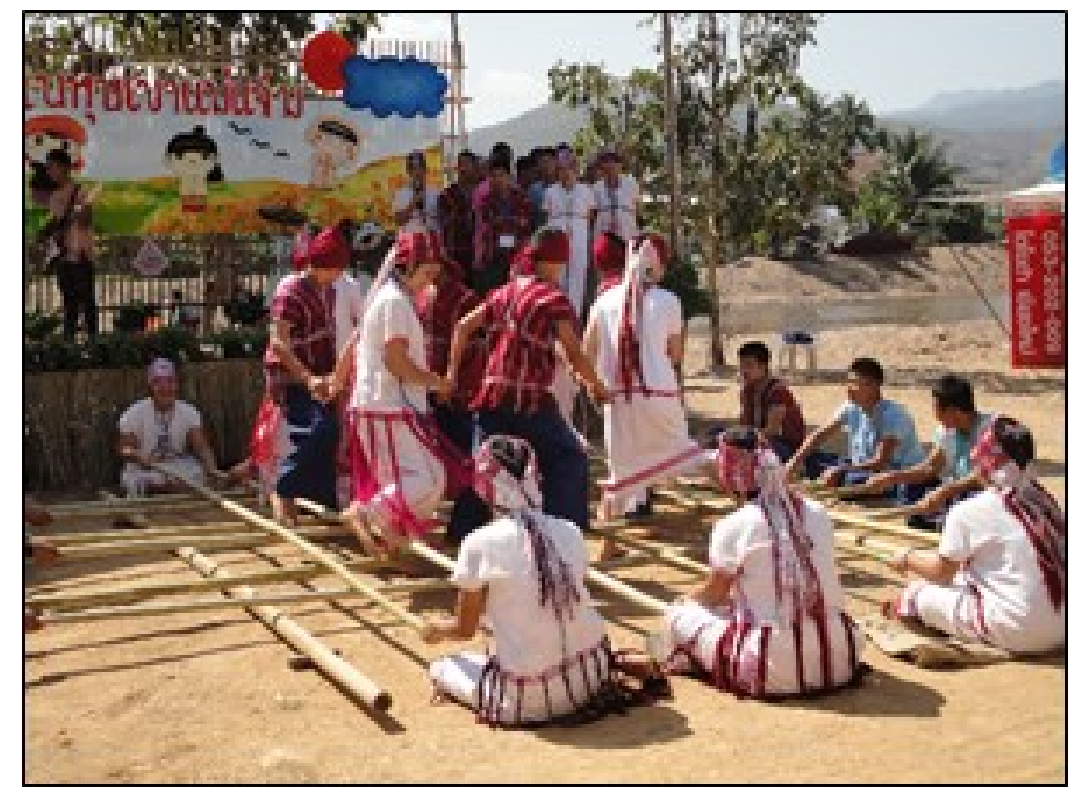

Figure 4. Performing the jikli bamboo dance (Source: Chi Suwichan Phattanaphraiwan, January 20, 2014) 


\section{Koe-lo (เก่อโละ)}

The koe-lo (Figure 5) is a Pgaz k'Nyau bamboo slit drum made from a joint of bamboo, with one long rectangular hole carved with the grain. A handle from the same stalk protrudes from one end, and a hardwood beater is attached with a string. Traditionally (and still today, in isolated villages with no electricity), the koelo was used to call community meetings with its sound, klo klo klo, which is also where the instrument gets its onomatopoeic name. The koe-lo is a struck idiophone capable of just one pitch (though it is not intentionally tuned to any frequency), which is determined by the bamboo joint's thickness, length and size. The pitch varies according to each individual instrument's construction, makeup and type of bamboo (such as the wasu, wasu doe and wawa or bong bamboo). It is usually played to accompany other instruments such as the tenaku, pi-ba, pi-u, saw-tru, paw-ku (bamboo xylophone), or others.

\section{History and Origins}

The koe-lo originated and was adapted from the thaw klaw, the pig's feeding trough, which was also made of bamboo (Phowa Khankaew, personal interview 2015). The thaw klaw would be struck at feeding time, and pigs would come running when they heard it. When the greater Pgaz k'Nyau community needed to gather, they also required a signalling tool to announce the meeting's impending commencement. The beating of the thaw klaw trough was used initially for this purpose, but it caused confusion (and noise) as it also attracted pigs expecting a feeding. The community leaders thus modified the bamboo trough design into a signalling tool. At first, it was just called klaw, but this eventually morphed to koe-lo. It is now considered an essential item for every household.

Phowa, 60-years-old, asserts that the best koe-lo is made from bamboo aged at least three years and perfectly straight. These characteristics produce the best sound quality. They also will not crack as easily. For this reason, most prefer to make them out of the wasu variety (black bamboo). Black bamboo hardens as it dries, resulting in a clear and loud sound quality when produced according to proper procedures.

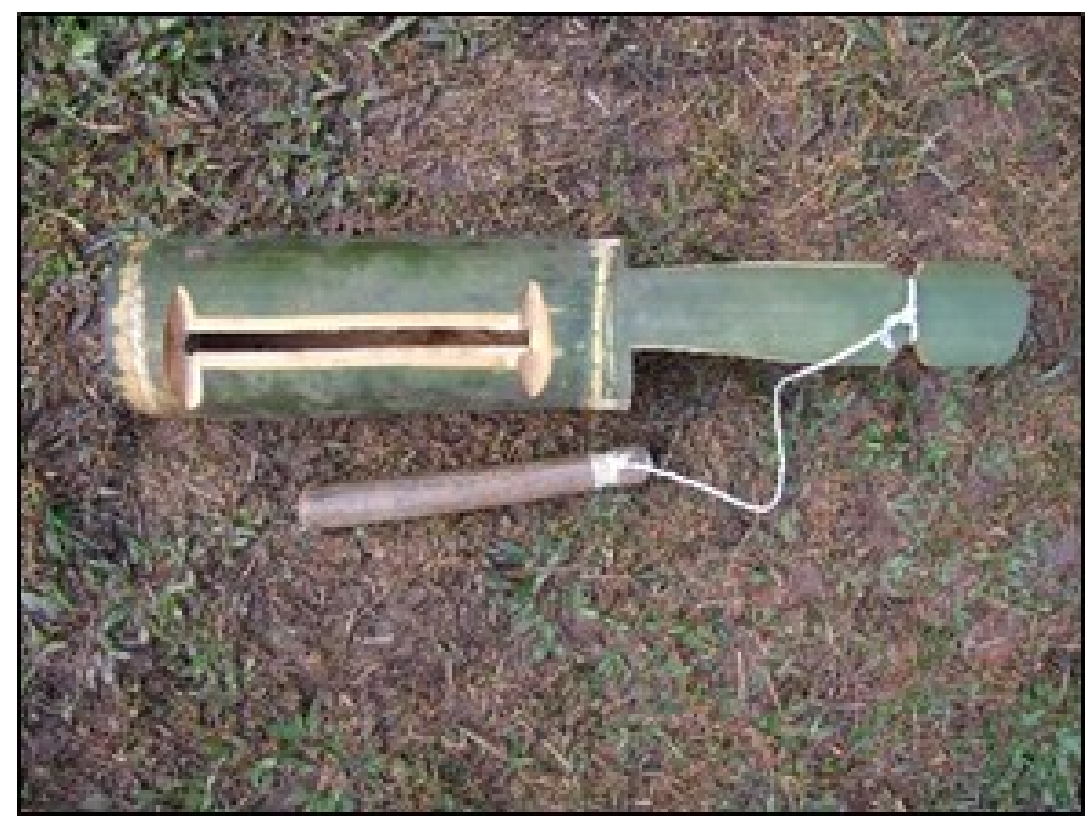

Figure 5. Picture of the koe-lo (Source: Chi Suwichan Phattanaphraiwan, December 30, 2013) 


\section{Restrictions in Constructing and Playing the Koe-lo}

The koe-lo is a signalling instrument, and each rhythmic pattern has a distinctive meaning.

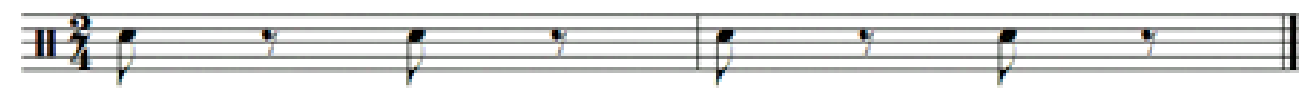

Figure 6. Koe-lo Pattern 1

The first pattern (Figure 6) is slow, providing a steady beat that is evenly spaced and slowly paced. This pattern signals a welcoming to all to come participate in an auspicious ceremony, such as a wedding, a house raising, or a wrist-tying ceremony (to secure the spirit to the body). As Phowa notes, the striking of a slow and steady beat is an expression of peace, simplicity, stability, or harmony. This rhythm is used at one's home or at the ceremonial site. It is not struck too strongly. When everyone hears it, they follow the sound to the site of the ceremony.

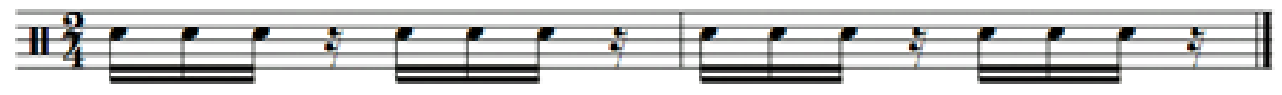

Figure 7. Koe-lo Pattern 2

The next pattern (Figure 7), a pattern of grouped threes, calls a community meeting. It signals that a gathering is needed to discuss an issue. This demonstrates community cohesiveness and cooperation; it is a sonic abstraction of collective actions such as lifting a pillar, where strength is coordinated by counting off, 'one, two, three!' This three-pattern rhythm thus semantically indexes a call to collective action and assistance, a sharing of strength, ideas, and communal duties. When the village leader hits this pattern from his house, every villager at his own home will strike their koe-lo in response and as means of extending the reach of the original message. The pattern will resound throughout the village, and none can claim they did not hear it or refuse a response. This is a sonic strategy of mobilisation that extends to all.

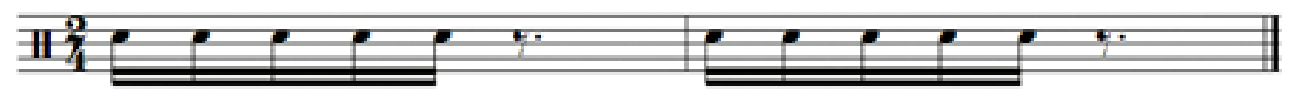

Figure 8. Koe-lo Pattern 3

The pattern of grouped fives (Figure 8) announces to the community that there has been a death. Among Pgaz k'Nyau communities, this five-beat pattern is thus paired to the notion of informing allhumans, the sacred, the spirits amongst us, the heavens, the stars and the hereafter - that the journey from haw kho khloe (literally 'the place of tears,' or the world of the living) to plue (the afterlife) is about to be made (Phattanaphraiwan, 2014, p. 12). This pattern will be beaten only at the home of the deceased and will not be returned by other homes. When it is heard, community members will proceed over to the house from where the signal has been sent. If anyone dares to beat their koe-lo in response, this is seen as a challenge to the spirits and an invitation of death to that home. 


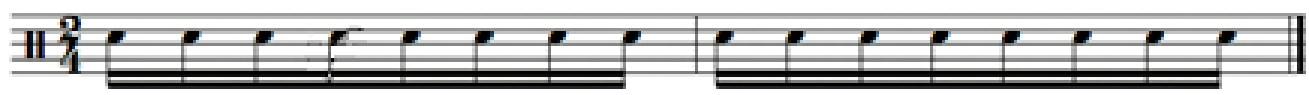

Figure 9. Koe-lo Pattern 4

The rapid-fire pattern (Figure 9) signals a matter of urgency or misfortune, such as a fire, invasion, plunder, brawl, injury, accident, or other emergency. The sound represents an adrenaline-fueled pounding heartbeat, an urgent need for assistance. Hitting the koe-lo in this way invites responses in-kind from other houses; the rapid-fire response signals that help is on the way and helps to broadcast the call. Other community members will immediately jump up to assist, grabbing a tool immediately available - machete, axe, gun, or stick - and rushing off to the scene to assist their fellow villagers in need.

\section{Values, Meaning and Philosophies underlying the Koe-lo}

The koe-lo is an important instrument of community cohesion. It facilitates communication, the flow of information and community response. It instigates action and reaction. If the community members did not tune in to each other, the koe-lo would be meaningless and, therefore, useless. It facilitates leadership: when an emergency occurs, the leader informs the community by sending various and variable signals as deemed necessary. And, for every call, there is a response-leadership is here acknowledged, chains of command are implemented, social relationships are confirmed and order is preserved.

\section{Saw-tru (ซอตรู่)}

The saw-tru (Figure 10) is a bowed tube zither typically made from wami bamboo (called sang in Thai, or dendrocalamus in the west). Nowadays there are a dwindling number of craftsmen who construct the saw-tru in Thailand. Our study focuses on a single site in Bangkloi village of Huay Mae Phrieng sub-district, Kaeng Krachan district, Petchaburi Province. This village claims to have just a single saw-tru performer remaining. The tradition is truly fragile and is on the brink of disappearance among Pgaz k'Nyau communities of Thailand.

\section{History and Origins}

Ms. Suayjae Gwabu (personal interview, 2015), the last remaining saw-tru player of upper Bangkloi, reminisced about her grandmother playing the $s a w-t r u$ when she was a child, reporting that,

The elders told us that in the past, the saw-tru was mostly a woman's instrument, though men could play it, too. The saw-tru was used to call the pigs back to the sty. In those days, the Pgaz k'Nyau used bamboo tubes, cut in half, as pig troughs. The women had many pigs and would play the saw-tru to call them. In the morning, after the pigs had been fed, they would free them to run around and forage. In the evening, the pigs' owners would play the saw-tru, and, since pig knew their owner's particular saw-tru sound, they would come running home when they heard their song. If a woman was an incompetent saw-tru player, her pigs might follow another's sound, and she'd have to spend her time running after her pigs to corral them.

There is a legend about this, too: Once there was a woman who played the saw-tru so well that even the wild boar of the forest could not resist its draw. They were compelled to follow the sound and never returned to the forest again. They were henceforth tamed, living in her stable. The pigs had distinctive features and were the first of a recognisably Pgaz k’Nyau breed of pigs with a long and pointy-head.

In some Pgaz k'Nyau communities, it is forbidden to play the saw-tru during the part of the season when the rice is turning yellow, as doing so might call the pigs out, resulting in the stalks being trampled. In the community of Pongluek-Bangkloi, the sound of the saw-tru had not been heard for many years, a 
disappearance that coincided with the decline in sightings of wild pigs. But in 2016, villagers started reintroducing the saw-tru and reportedly observed a noticeable increase in the wild pig population in the surrounding forests. Mr. Pru, the village headman, claimed,

As soon as we migrated to this place (Pongluek-Bangkloi), we could not make a living. We were limited in land sufficient to grow rice, so we didn't plant rice. We saw no reason to play the saw-tru. But now that we've reintroduced it, we have noticed more and more pigs in the forest. There were hardly any there before, but now we want to have the saw-tru played more. However, we only have saw-tru player left.

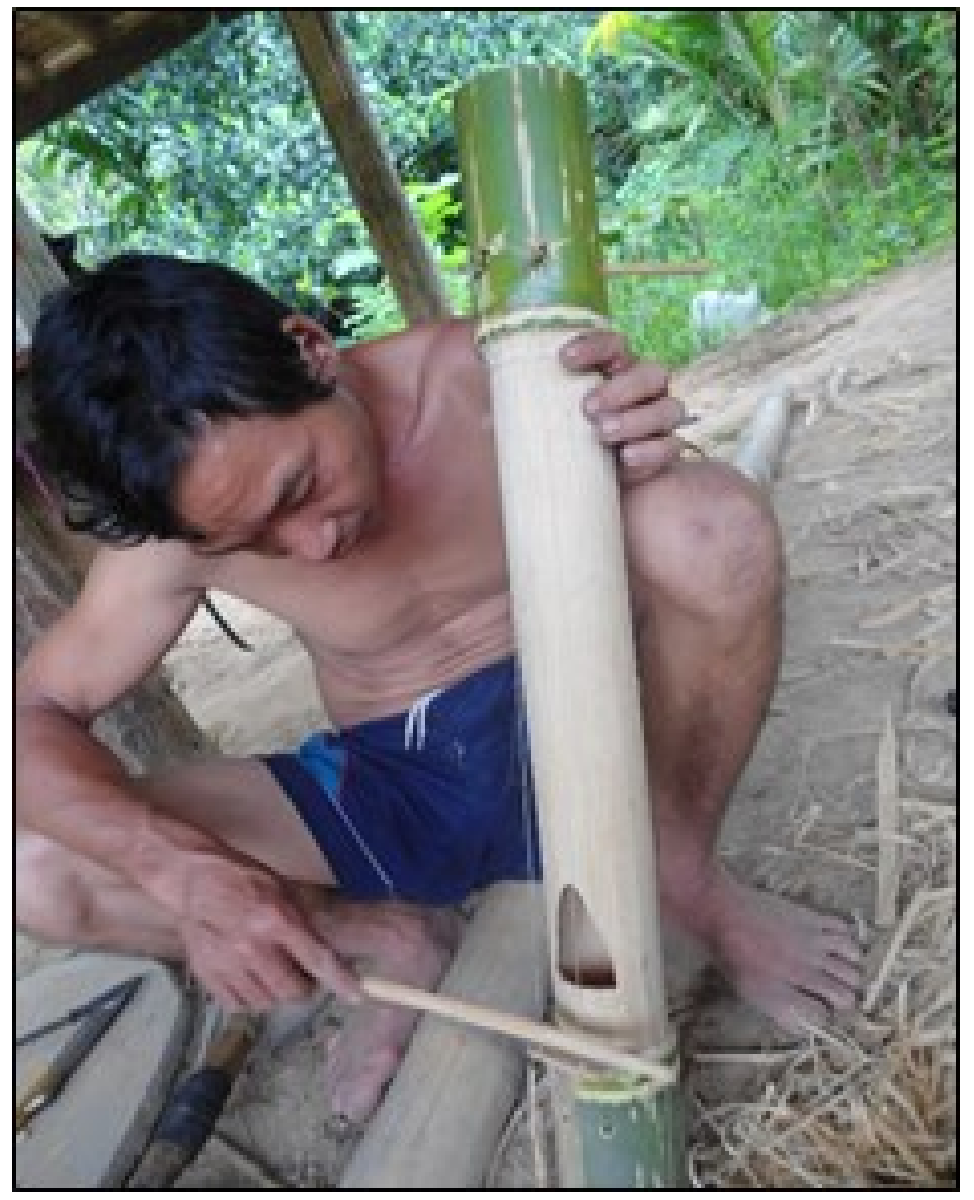

Figure 10. Bowed saw-tru (Source: Chi Suwichan Phattanaphraiwan, October 11, 2013)

\section{Restrictions in Constructing and Playing the Saw-tru}

The bamboo chosen must be about three inches in diameter. If it is smaller than this, the sound will not be sufficient. If larger than this, it will be difficult to wrap one's fingers around the neck to stop the strings. As for the type and desired characteristics of the bamboo used, the preferred bamboo best suited for making a saw-tru is said to be that which has died on its own in the forest of its own accord, naturally, as it is driest and most durable. According to Suayjae, in the past, Pgaz K'nyau would never use bamboo unless it was already dead and dried out, since they believed that if one used bamboo that was not already dead, the grove you cut from would collapse, and when you played the saw-tru you had made from it, spirits would be drawn from the forest into your community, wreaking havoc on the living. 


\section{Values, Meaning and Philosophies underlying the Saw-tru}

An underlying meaning of the saw-tru points to the fact that a naturally-deceased bamboo grove is indeed rare, and, therefore, the implied production of a saw-tru instrument requires patience. Temperance, too, is implied: the Pgaz K'nyau have a great need for this instrument, but it must not be demanded or coerced from nature. A grove cannot be violated simply because humans require its bounty. Thus, sustainability and patience are built into this traditional knowledge and practice. The woman who wants a saw-tru must wait for the grove's natural process to play out, working with nature's cycles rather than asserting human will and domination.

There is also the aforementioned belief that the saw-tru has the power to communicate with pigs (especially wild pigs). As any communication requires an appropriate atmosphere, it is not just the performer who must have the right attitude of tranquillity - the community atmosphere must also be peaceful. Otherwise, it is not easy for the not-especially-loud saw-tru to be heard from a distance. The village context requires a degree of calm silence. Stillness is thus a form of strength and is seen as a vessel for communication with nature that requires focused, communal concentration. It is a relationship enabled by stillness and attention.

The traditional belief in the sonic superiority of naturally-deceased bamboo has clear connections to natural resource management. That naturally-dried bamboo sounds better is more than just a saying. The underlying meaning is one of preservation, an understanding that the construction of such a desirable and useful instrument requires that one pay attention to and wait for the proper season, that one be in tune with nature, with the forest. Beliefs maintain that to destroy one part of the forest has an effect on the rest. Using a naturally-deceased bamboo may or may not actually make for an aesthetically or objectively verifiable 'prettier' sound, but what is clear is that the addition of sonic aesthetics to natural resource utilisation results in a reduction of forest destruction. However, this same restriction is also the reason for the decrease in sawtru knowledge, performance and construction. It is becoming increasingly rare.

\section{Analyses and Applications}

As Waksman implies, a close examination of musical instruments' situatedness within a culture leads to an understanding of them "as objects that, in being used to create music, also work to recreate the cultures they inhabit" (p. 257). Musical instruments are not just artefacts in or of a culture but operate as culture, an ecomusicological take on a long-established ethnomusicological paradigm (Herndon and McLeod, 1982). Observations, applications and implications of these bamboo musical instruments illustrate that, for this indigenous Pgaz k'Nyau population, music and musical instruments' meanings and functions extend into to the realm of resource and relationship maintenance. Bamboo and its sonic repurposing plays an instrumental role in affecting the balance of Pgaz k'Nyau society in five important ways outlined below.

Before jumping to the list, though, a note on balance (or equilibrium) is in order, lest we be accused of being lured by popular idealistic "nature interrupted" or 'balance-of-nature' paradigms that Titon warns are romanticizing misinterpretations of ecomusicology as a field (2018, pp. 259-261). While some of the quotations and standpoints above may imply or spring from well-worn tropes of the loss of the pristine or laments of a triumph of modernity over indigenous values, Titon and other ecomusicologists (Allen and Dawe, 2016; Perlman, 2012; Titon, 2013) point to the emergent scientific paradigm of ecosystemic resilience, adaptability, or "disturbance-and-change" models that are more useful and more accurate when viewing ecosystems as relationships in flux. Culture (a system of learned and shared beliefs, values, assumptions, and meanings) is not stagnant or rigid; neither is nature (and neither are the two cleanly distinguished in the Pgaz k'Nyau understanding). They are signified and made significant through interaction rather than isolation. Both are responsive, and in ecomusicological readings, mutually and symbiotically so. To this end, bamboo instruments are instrumental to reifying, adjusting, mediating, and formalising relationships between the various and fuzzy categories of actors integral to Pgaz k'Nyau society. Notably, the compound Sgaw Karen label denoting equilibrium, tah paw mi law saw, includes both 'harmony' (tah paw) and 'connection' (law $s a)$. 
In the five categories below, it is not musical instrument that acts upon human to adjust behaviour in order to produce a result in nature in a one-way, prescriptive teleology, context-based or not. Rather, equilibrium is a constant negotiation, mediated through and by cultural values and the signification of sound, object, concept and behaviour. Agreeing with Titon that there can only be 'temporary equilibria' (2018, p. 260) in a dynamic setting, we turn to the ways in which musical instruments are a part of the cultural and negotiated process of valuing, modifying, signifying and balancing complex relationships. As we outline below, and as Titon notes elsewhere, "Sound turns space into sacred place; it enables communication among animals, including humans; and it puts beings into co-presence with one another and their environments" (2013, p. 17). We frame this signifying and relationship-altering action as negotiating that equilibrium, with the instrument being instrumental in the following five interactive relationships.

\section{Bamboo: Instrumental to Pgaz k’Nyau Self-equilibrium}

Playing the pi-u/u-maw heightens awareness of the life cycle through both its sonic and its physical presence at birth and death. All are born, live and ultimately die. Sending breath into the pi-u/u-maw can produce sound and melody, a sound that ceases when breathing does. In the blowing of the $p i-u / u-m a w$, and especially with the free-reed $p i-b a$ (where sound is produced by breathing in as well as out), there is inhalation, exhalation and expiration. In addition to this, the restrictions on the performance and construction of the instrument require thoughtfulness and consideration. They encourage a command of the self (e.g., the respectful playing posture produced with the $p i-b a$ ), and a call to preserve rather than destroy life (human and animal). With the saw-tru, too, one must possess an inner calm and awareness in order to be able to communicate with the pigs. These are all ways that the self is reified, made cognizant and tempered through interaction with and through the musical instruments.

\section{Instrumental to Human-Human Equilibrium}

A pattern struck and heard (i.e., signified and interpreted) on the koe-lo can instantly alter a social space. When the koe-lo is sounded, both the one striking it and the one hearing it must tune in and analyse the soundscape to determine the message being communicated. Community members must respond to each other appropriately and must be willing to help where needed. For the $p i-u$, sonic and physical presence communicates the arrival of new life. It informs the community of a birth and brings news of a new member with whom all will have some relationship with going forward. The pi-ba also calls attention to respectful social relations in the mere posture required in its playing: palms pressed together (wai greeting of respect) while facing the audience. Here, to play is to show respect, and to name the instrument is to speak the literal word ('flute of respect'). Bamboo is instrumental as mediating and embodying community relations.

\section{Instrumental to Human-Animal Equilibrium}

This is shown in the restrictions in place concerning $p i-b a$ construction, where humans are forbidden from killing rats or ants, both of which, coincidentally, have an important place in the food chain. Additionally, the beliefs surrounding the playing of the saw-tru as a means of communicating with wild pigs points to this goal of adjusting an imbalance between human and animal communities. Music thus mediates human-animal interactions and reminds the Pgaz k'Nyau of the interdependent nature of the relationship.

\section{Instrumental to Human-Forest Equilibrium}

The restrictions associated with saw-tru production point to this ideal, as one is required to find an alreadydeceased bamboo grove rather than cut within a fresh, living grove. This stricture stresses preservation, as do the origin stories of both the saw-tru and the koe-lo - both of these are adapted from pig troughs, which shows how natural resources were used and repurposed to their fullest. Similar notions can be drawn from the procedures for selecting bamboo for the pi-u, which cannot be made from young bamboo. Such taboos 
demonstrate local wisdom, foresight and balance in natural resource management methods, and they are reinforced by musical aesthetics. When such cultural restrictions are followed, the result is ideally a Pgaz k'Nyau community that does not over-harvest or otherwise exhaust their resources. Sustainable resource management is encoded into musical instrument production and musical participation. ${ }^{7}$

\section{Instrumental to Human-Supernatural Equilibrium}

As seen in the $p i-u / u-m a w$, music traditionally was not meant as sound only for the living but was heard by the deceased-turned-spirit as well. It accompanied the bamboo jikli dance at funerals, and it was played at the gravesite in the forest, as it was believed it could trick the spirits so that they did not follow the living back to the village site. Pgaz k'Nyau animist traditions held that if the spirits of the deceased return to the community, they could attract the spirits of the living to return to the afterlife with them, especially those of the sick, weak, very young, or pregnant, who would not return to the living once they left. But it is said that playing the $p i-u$ while dancing jikli preserves the boundary between living and deceased, keeping each in their place and out of the other's territory.

Transecting this human-supernatural balance, funeral restrictions also benefit the forest, as the forest gravesites in the animist tradition (left alone due to the divide between the living and the supernatural) become nurseries for wild plants and animals, unobstructed by humans and preserved as sacred ecosystems left to their own devices. This and other blurred boundaries above indicate that categories above are not especially rigid but are in fact interactive and co-dependent-here, the human-spiritual relations affect the forest, which in turn has benefits for wild animals that interact with humans and so on. ${ }^{8}$ Thus, the five categories collectively and collaboratively integrate communities, the self, the natural world and the supernatural, and bamboo musical instruments play a clear role in facilitating this process for the Pgaz k'Nyau. The 'meanings' of the musical instruments are thus not necessarily underlying or inherent but rather become emergent and observable through processual interaction and application (Tan, 2014, p. 323). Labels may be necessary, but they are certainly not fixed.

\section{Conclusion}

Bamboo instruments and musical practice confirm eco-aware Karen values at work, for internal and external purposes. The 'eco-friendly Karen' label attributed to and claimed by Pgaz k'Nyau artists, activists and academics (Phattanaphraiwan, 2011, pp. v-vii) is a powerful and necessary trope, given national narratives that within living memory (and uninformed contemporary stereotypes) painted all 'hill tribes' (chao khao) as problematic forest destroyers encroaching upon and degrading national forests (Buadaeng, 2006, pp. 371375). Pgaz k'Nyau bamboo instruments and the cultural value added to or gained from interaction with endangered groves reinforce notions of a responsive and non-threatening ethnic (agri)cultural behaviour. Waskman notes that instruments don't "have" built-in authenticity but rather are positional means for lending, constructing, or projecting messages that afford agency (p. 256). To lose these bamboo groves, instruments, and elders with expert knowledge is to lose the tangible evidence and practice of claimed Pgaz k'Nyau sustainability and symbiosis. And to be a "forest destroyer" is to be an enemy of or problem to the Thai state and Royal Forestry Department, which have taken aggressive action in evicting non-Thai 'squatters' from government lands (Buergin, 2003; Forsyth and Walker, 2008, p. 48). Thus, maintaining, confirming, and projecting an image of the Pgaz k'Nyau eco-friendly tradition has internal and external, political and material and abstract and concrete implications for the Pgaz k'Nyau in Thailand. Bamboo instruments place their makers (within an eco-friendly label and discourse) and make the place. 


\section{Endnotes}

1 'The' Karen are a really multi-factioned, or 'highly plural' society (South, 2007, p. 56), a conglomeration of peoples divided into sub-groups, dialects, and even through religious practice. Hinton (1983) famously framed the discussion as one of existence: is there, in fact, such a group? This paper covers but one part of a complex amalgamation: the 'Sgaw Karen' in Thailand, who call themselves 'Pgaz k'Nyau' (a term meaning 'human'). This particular spelling comes from the Catholic Romanised script (final consonants are not pronounced and refer to tones).

${ }^{2}$ Various news outlets and NGOs drew attention to the disappearance of Pgaz k'Nyau activist Pawlajee Rakjoncharoen (AKA 'Billy') who was arrested in Kaeng Krachan National Park (and allegedly 'disappeared') for illegally gathering honey. This was after he had brought a lawsuit against park authorities for the illegal confiscation of Pgaz k'Nyau homes and property in the park. The joint statement by American NGO Cultural Survival, the Network for Indigenous Peoples in Thailand and Asia Indigenous Peoples Pact can be read at https://www.culturalsurvival.org/sites/default/files/media/thailandupr-sep2015-final_0.pdf. Pgaz k'Nyau villagers brought a case against the park authorities, who cited government ownership of the land, evicted the Pgaz k'Nyau and burned their homes and belongings. The case was brought to court in 2016, where judges levied a fine on the park officials for not removing the belongings before burning the houses down but otherwise affirmed that the eviction was legal (Rujivanarom, 2016; also see http://www.forestpeoples.org/topics/rights-land-naturalresources/news/2016/09/thailand-karens-appeal-court-verdict-legalizing-th). Billy's bones were discovered in September of 2019 and at the time of this paper's writing, the case is being investigated as murder (see https://www.nationthailand.com/news/30376275).

3 This research project was assisted by students and merged into the curriculum of Chi Suwichan's geo-cultural management courses at Bhodiwichalai College, which is located near the Thai-Myanmar border town of Mae Sod in Tak Province, a college with a student body populated primarily by non-Thai ethnic groups.

${ }^{4}$ Update: as this manuscript made its way through peer review, Jaw-bwae passed away. Ongoing in the PI's research agenda is a pilot curriculum for eventual use in public schools in the Mae Sod area, where Karen students can learn to make and play instruments studied here (as well as the tehnaku).

${ }^{5}$ While some claim that koejaklaw is the Pgaz k'Nyau adaptation of Buddha, called koejablaw, this is not the case, as koejaklaw appears in legend that predate exposure to Buddhism (Phattanaphraiwan, personal communication).

${ }^{6}$ As observed by the principal investigator, many primary growth spaces (once marked by biodiversity) had been converted to cash crops in the 1980s (Kunstadter, 1983, p. 336), yielding wheat, avocado or marketable products, and not much space was left for bamboo, and saw khae is on the decline.

${ }^{7}$ Chi's first publication, Rao Khue Tehnaku [I am Tehnaku], features a few chapters devoted to conservational measures in tehnaku construction, i.e. where specific trees are preferred (best are those naturally deceased and already dried-out). If living trees are to be cut down, they should be cut at knee-height so that buds can sprout from them again. To cut it at ankle-level is unsustainable and a violation of this human-forest relationship, as the forest sustains human life (2011, pp. 101-102). A modern rationale for this, too, is in direct response to Thai authorities who accused the Karen of being forest destroyers. By pointing to deep-held musical traditions and instrument manufacturing procedures, the argument can be made for an eco-friendly tradition that specifically encodes environmental preservation into cultural practice (see Fairfield, 2013)

${ }^{8}$ This relationship between the Pgaz k'Nyau self and various others is mediated by bamboo non-musically, too. After a child is born, his or her umbilical cord will be placed inside a bamboo joint, which is then tied to a tree. The tree can never be cut down and is paired with the human for life.

\section{References}

Allen, A. and Dawe, K. (Eds). (2016). Current directions in ecomusicology: Music, culture, nature. New York, NY: Routledge. https://doi.org/10.4324/9781315752938

Buergin, R. (2003). Trapped in environmental discourse and the politics of exclusion: Karen in the Thung Yai Naresuan Wildlife Sanctuary in the context of forest and hill tribe policies in Thailand. In Claudio O. Delang (ed.), Living at the edge of Thai society: The Karen in the highlands of northern Thailand. London: Routledge Curzon. https://doi.org/10.4324/9780203356456

Kesmanee, C. (1994). Dubious development concepts in the Thai highlands: The chao khao in transition. Law \& Society review, 28(3), 673-686. https://doi.org/10.2307/3054088

Dawe, K. (2016). Materials matter: Towards a political ecology of musical instrument making. In Aaron Allen and Kevin Dawe (Eds.), Current directions in ecomusicology: Music, culture, nature. New York, NY: Routledge.

Delcore, H. (2007). The racial distribution of privilege in a Thai national park. Journal of Southeast Asian Studies 38(1), 83-105. https://doi.org/10.1017/s0022463406000944 
Dirksen, Rebecca. (2019). Haiti's drums and trees: Facing loss of the sacred. Ethnomusicology 63(1), 43-77. https://doi.org/10.5406/ethnomusicology.63.1.0043

Fairfield, B. (2013). I am Tenaku: The reification and textuality of "Chi” Suwichan's Karen harp. Ethnomusicology Review 18. https://www.ethnomusicologyreview.ucla.edu/journal/volume/18/piece/697

Forbes, A. (1982). Thailand's Muslim minorities: Assimilation, secession, or coexistence? Asian survey, 22(1), 10561073. https://doi.org/10.1525/as.1982.22.11.01p0424w

Forsyth, T. \& Walker, A. (2008). Forest guardians, forest destroyers: The politics of environmental knowledge in northern Thailand. Seattle: University of Washington Press.

Jonsson, H. (Autumn 2004). Mien alter-natives in Thai modernity. Anthropological quarterly, 77(4), 673-704. https://doi.org/10.1353/anq.2004.0056

Jory, P. (1999). Political decentralization and the resurgence of regional identities in Thailand. Australian Journal of Social Issues, 34(4), 337-352. https://doi.org/10.1002/j.1839-4655.1999.tb01084.x

Hayami, Y. (1996). Karen tradition according to Christ or Buddha: The implications of multiple reinterpretations for a minority ethnic group in Thailand. Journal of southeast Asian studies, 27(2), 334-349. https://doi.org/10.1017/s0022463400021093

Hinton, P. (1983). Do the Karen really exist? In John McKinnon and Wanat Bhruksasri (Eds.), Highlanders of Thailand. Kuala Lumpur: Oxford University Press.

Herndon, M. and McLeod, N. (1982). Music as culture, $2^{\text {nd }}$ ed. Darby, PA: Norwood Editions.

Kunstadter, P. (1983). Karen agro-forestry: Processes, functions, and implications for socio-economic, demographic, and environmental change in northern Thailand. Mountain research and development, 3(4), 326-337. https://doi.org/10.2307/3673036

Buadaeng, K. (2006). The rise and fall of the Tribal Research Institute (TRI): 'Hill Tribe' policy and studies in Thailand. Southeast Asian studies, 44(3), 359-384.

McKinnon, K.. (2011). Development of professionals in northern Thailand: Hope, politics and practice. Honolulu: University of Hawai'i Press.

Singkiree, N. (6 September 2019). Park official told to blame boss for Billy’s death. Bangkok Post. https:/www.bangkokpost.com/thailand/general/1744429/park-official-told-to-blame-boss-for-billys-death.

Odochao, J., Nakashima, D., and Vaddhanaphuti, C. (2006). An education rooted in two worlds: The Karen of northern Thailand. International social science journal, 58(187), 117-120. https://doi.org/10.1111/j.14682451.2006.00608.x

Perlman, M. (2012). Ecology and ethno/musicology: The metaphorical, the representational, and the literal. Ecomusicology newsletter 1(2), 15-21.

Laungaramsri, P. (2003). Constructing marginality: The 'Hill Tribe' Karen and their shifting locations within Thai state and public perspectives. In Claudio O. Delang, Editor, Living at the edge of Thai society: The Karen in the highlands of northern Thailand. New York: Routledge.

Rujivanarom, P. (7 September, 2016). Court rules in favour of national parks department in Kaeng Krachan encroachment case. The Nation.

Small, C. (1998). Musicking: The meanings of performing and listening. Wesleyan University Press.

South, A. (2007). Karen nationalist communities: The "problem" of diversity. Contemporary Southeast Asia $29(1), 2007$.

Wongthes, S. (2011) The musical ancestors of Thai music in Suwannaphum. In Suwichan Phattanaphraiwan (Chi), Phleng tawng haam khawng Pgaz k'Nyau. Bangkok: Santisiri Press.

Phattanaphraiwan,S (“Chi”). (2014). Phleng tawng haam khawng Pgaz k'Nyau [Forbidden Songs of the Pgaz K'Nyau]. Bangkok: Santisiri Press.

Phattanaphraiwan,S (“Chi”). (2011). Rao khue tehnaku [I am tehnaku]. Chiang Mai: Lanna Media Productions.

Tan, G. (2014). An ecology of religiosity: Re-emphasizing relationships between humans and nonhumans. Journal for the study of religion, nature and culture 8(3), 307-28. https://doi.org/10.1558/jsrnc.v8i3.307

Numnonda, T. (1978). Pibulsongkram's Thai nation-building programme during the Japanese military presence, 19411945. Journal of southeast Asian studies, 9(2), 234-247. https://doi.org/10.1017/s0022463400009760

Winichakul, T. (2011). Siam's colonial conditions and the birth of Thai history. In Volker Grabowsky, Editor, Southeast Asian historiography unravelling the myths: Essays in honour of Barend Jan Terwiel. Bangkok: River Books.

Titon, J.T (2018). Afterword: Ecomusicology and the problems in ecology. MUSICultures 45(1\&2), $255-264$.

Titon, J.T. (2016). Why Thoreau? In Aaron Allen and Kevin Dawe (Eds.), Current directions in ecomusicology: Music, culture, nature. New York, NY: Routledge.

Titon, J.T.. (2013). The nature of ecomusicology. Musica e Cultura: Revista da ABET 8(1), 8-18.

Walker, A. (September 2001). The 'Karen Consensus': Ethnic politics and resource-use legitimacy in northern Thailand. Asian ethnicity, 2(2), 145-162. https://doi.org/10.1080/14631360124782 
Waksman, S. (2003). Reading the instrument: An introduction. Popular music and society 26(3), 251-261.

https://doi.org/10.1080/0300776032000116941

\section{Biography}

'Chi'Suwichan Phattanaphraiwan received his $\mathrm{PhD}$ in Art and Culture Research from Srinakharinwirot University. He is an internationally-renown musician, activist, and assistant professor of Geo-Cultural Management at Bodhivijjalaya College, Srinakharinwirot University in Mae Sod, Tak. He has published two books on Pgaz k'Nyau music, Rao Khue Tehnaku (2011) and Phleng Tong Haam Khong Pga k'Nyau (2014), is actively involved in the Karen Network for Culture and the Environment, serves as vice president of the Foundation for Culture and Environment, Southeast Asian chapter (FCESA), Chairperson of ASEAN Ethnic Creative Foundation (AEC) and recently cofounded the Karen Community Eco museum.

Benjamin Fairfield received his PhD and MA in Ethnomusicology from the University of Hawai' $i$ at Mānoa. He served as a Peace Corps volunteer (community-based organizational development) in Chiang Mai, Thailand, from 2007-2009, where he lived in a Karen (Pgaz k'Nyau) village. His current research focuses on ethnic identity in northern Thailand as mediated by music with particular emphases on participatory genres and religion. He has collaborated with Chi Suwichan on two book translations and currently serves as affiliate faculty at the University of Hawai'i Music department and the Center for Southeast Asian Studies. 